\title{
Association of gene polymorphism of the fat-mass and obesity-associated gene with insulin resistance in Japanese
}

\author{
Izumi Shimaoka $^{1}$, Kei Kamide ${ }^{1}$, Mitsuru Ohishi ${ }^{1}$, Tomohiro Katsuya ${ }^{2}$, Hiroshi Akasaka ${ }^{3}$, Shigeyuki Saitoh ${ }^{3}$, \\ Ken Sugimoto $^{1}$, Ryousuke Oguro ${ }^{1}$, Ada Congrains ${ }^{1}$, Tomomi Fujisawa ${ }^{1}$, Kazuaki Shimamoto ${ }^{3}$, Toshio Ogihara ${ }^{1}$ \\ and Hiromi Rakugi ${ }^{1}$
}

It was reported that gene polymorphisms in the fat-mass and obesity-associated gene (FTO) were associated with obesity and diabetes in several genome-wide association studies. A recent report indicated that FTO-knockout mice exhibited phenotypes of skinny body shape and normal metabolic profiles. Thus, FTO could be important in metabolic disorders. The aim of this study was to clarify the role of single nucleotide polymorphisms (SNPs) in FTO in metabolic disorders such as hypertension, obesity, diabetes, dyslipidemia, insulin resistance and metabolic syndrome in the Japanese general population using data from a cohort study in Hokkaido, namely the Tanno-Sobetsu study. Written informed consent for the genetic analysis was obtained from each subject participating in the study. A total of 1514 subjects were genotyped by TaqMan PCR methods for three SNPs, rs9939609, rs1121980 and rs1558902, in FTO. Association analyses between the SNPs and metabolic parameters were performed. Although two SNPs, rs9939609 and rs1558902, were not significantly associated with hypertension, obesity, metabolic syndrome or any metabolic parameters, additive and recessive models of rs 1121980 were strongly associated with plasma immunoreactive insulin (IRI) level and homeostasis model assessment insulin resistance (HOMA-IR), even after adjusting for confounding factors such as age, gender and body mass index. A haplotype of three SNPs was also significantly associated with IRI and HOMA-IR. One SNP, rs1121980, and a haplotype of three SNPs in FTO that contains this SNP, might be important in the progression of insulin resistance in Japanese subjects.

Hypertension Research (2010) 33, 214-218; doi:10.1038/hr.2009.215; published online 15 January 2010

Keywords: FTO; insulin resistance; metabolic syndrome; obesity; SNP

\section{INTRODUCTION}

Metabolic syndrome (MS) consisting of central obesity, high blood pressure, abnormal glucose tolerance or abnormal lipid profiles is considered an independent risk factor for cardiovascular diseases such as ischemic heart disease and stroke. ${ }^{1,2}$ In Japan, central obesity based on visceral fat accumulation is an essential diagnosis criterion for MS. One of the main pathways to central obesity is considered to be an imbalance in the secretion of adipocytokines from adipose tissues and subsequent following insulin resistance. ${ }^{3}$ Genetic background influences metabolic disorders. Recently, several genome-wide association studies revealed that single nucleotide polymorphisms (SNPs) of the fat-mass and obesity-associated gene (FTO) might be predisposing factors for obesity, diabetes and MS.4-6

Recently, it was reported that FTO-knockout mice showed several characteristic phenotypes, which included skinny body shape and normal metabolic profiles. ${ }^{7}$ Thus, FTO could be important in fat accumulation and the regulation of glucose or lipid metabolism.
In previous genetic analyses, SNPs rs9939609, rs1121980 and rs1558902 in FTO were strongly associated with obesity, defined by body mass index (BMI). ${ }^{8-11}$ There remain questions concerning whether these SNPs affect obesity and other metabolic disorders in Japanese subjects, who have a quite different body shape and diet from subjects in Western countries. Furthermore, the allele frequencies of FTO SNPs in Japanese subjects are quite different from those in Caucasian subjects (http://hapmap.ncbi.nlm.nih.gov/).

It was reported by Japanese investigators that rs1558902, but not rs9939609, in FTO was associated with BMI in a case (severe obesity group: $\mathrm{BMI} \geqslant 30 \mathrm{~kg} \mathrm{~m}^{-2}$ )-control (nonobesity group: $\mathrm{BMI} \leqslant 23 \mathrm{~kg} \mathrm{~m}^{-2}$ ) study. ${ }^{9}$ However, there are no reports on investigations of the relationship between FTO SNPs and metabolic disorders including hypertension, obesity, DM and MS as well as other parameters such as insulin resistance in the Japanese general population. In this study, we investigate the role of FTO SNPs in metabolic disorders in a cohort study, namely, the Tanno-Sobetsu study in Hokkaido, northern Japan.

${ }^{1}$ Department of Geriatric Medicine, Osaka University Graduate School of Medicine, Suita, Osaka, Japan; ${ }^{2}$ Department of Clinical Gene Therapy, Osaka University Graduate School of Medicine, Suita, Osaka, Japan and ${ }^{3}$ Department of Internal Medicine II, Sapporo Medical University, Sapporo, Hokkaido, Japan 


\section{METHODS}

\section{Study subjects}

We recruited 1514 subjects (803 in Tanno town and 711 in Sobetsu town) who had undergone medical checkups in these towns in Hokkaido, Japan, in 2002. The detailed epidemiological findings have already been reported. ${ }^{12-17}$ Subjects completed a standard questionnaire regarding their medical history, and smoking and drinking habits. We measured the systolic blood pressure (SBP), diastolic blood pressure (DBP), BMI, abdominal circumference, total cholesterol, triglyceride, high-density lipoprotein cholesterol, plasma glucose and immunoreactive insulin (IRI). Blood samples were collected during fasting in the early morning. Obesity was defined as a BMI $>25 \mathrm{~kg} \mathrm{~m}^{-2}$. Dyslipidemia was defined as total cholesterol $\geqslant 220 \mathrm{mg}$ per $100 \mathrm{ml}$ and/or drug treatment for hypercholesterolemia. Diabetes was defined as fasting blood sugar $\geqslant 126 \mathrm{mg}$ per $100 \mathrm{ml}$ and/or drug treatment for hyperglycemia. The Japanese definition of MS ${ }^{18}$ was used as the diagnosis for MS. Briefly, criterion 1 and two of criteria 2-4 needed to be met.

1. visceral fat: (male) abdominal circumference $\geqslant 85 \mathrm{~cm}$ (female) abdominal circumference $\geqslant 90 \mathrm{~cm}$

2. lipid abnormality: treatment for dyslipidemia or triglyceride $\geqslant 150 \mathrm{mg}$ per $100 \mathrm{ml}$ and/or high-density lipoprotein cholesterol $<40 \mathrm{mg}$ per $100 \mathrm{ml}$

3. blood pressure: treatment for hypertension or $\mathrm{SBP} \geqslant 130$ and/or $\mathrm{DBP} \geqslant 85 \mathrm{~mm} \mathrm{Hg}$

4. hyperglycemia: treatment for diabetes or fasting blood sugar $\geqslant 110 \mathrm{mg}$ per $100 \mathrm{ml}$.

Homeostasis model assessment insulin resistance (HOMA-IR) was used to determine insulin sensitivity, and was calculated as plasma glucose (mg per $100 \mathrm{ml}) \times$ IRI $\left(\mu \mathrm{U} \mathrm{ml}^{-1}\right) / 405 .{ }^{19}$ Blood pressure was measured twice after $5 \mathrm{~min}$ of rest, with the subjects seated. Hypertension was defined as SBP $\geqslant 140$, DBP $\geqslant 90 \mathrm{~mm} \mathrm{Hg}$ or the current use of antihypertensive agents. Three hundred and ninety-five subjects were taking antihypertensive agents, and these subjects were included in the study. Individuals undergoing medical treatment and receiving diet therapy or exercise therapy for diabetes mellitus $(n=84)$ were also included. Precise information on the types of antihypertensive agents or the nature of the treatment for diabetes was not obtained. All participants gave written informed consent to participate in the genetic analyses and in all other procedures associated with the study. The ethics committee of Osaka University approved the study protocol. The final number of subjects participating in the genetic study was 1488

\section{Genotyping}

Genomic DNA was extracted from $200 \mu$ l of buffy coat using a QIAamp DNA Blood Kit (Qiagen, Hilden, Germany). We selected three SNPs, rs9939609, rs1121980 and rs1558902, in FTO, which were identified as being associated with obesity and/or diabetes in previous reports. ${ }^{6,9,20,21}$ These SNPs were genotyped using TaqMan PCR methods with the following probes: C_30090620_10 for rs9939609, C_2031261_10 for rs1121980 and C_ 8917111_10 for rs1558902 (Applied Biosystems, Foster City, CA, USA).

\section{Statistical analysis}

Hardy-Weinberg equilibrium was calculated by a $\chi^{2}$-test. Linkage disequilibrium was evaluated by SNP Alyze version 2.1 (DYNACOM Co., Ltd, Mohara, Japan). Associations between the polymorphisms and clinical variables were analyzed using one-way analysis of variance and analysis of covariance adjusted for confounding factors. Differences in genotype or allele distribution were examined by $\chi^{2}$-analysis. All numerical values are expressed as mean \pm s.d. Values of $P<0.05$ were considered to indicate statistical significance. To adjust for multiple testing of the three gene polymorphisms by Bonferroni's correction, we arbitrarily adopted $P<0.017(=0.05 / 3)$ as the level of statistical significance. Haplotype estimation was performed by the expectation-maximization algorithm. All analyses except analysis of covariance were performed with JMP statistical software (version 5; SAS Institute Inc., Cary, NC, USA), and analysis of covariance was performed with SPSS $\alpha$ statistical software (release 11.0.1; SPSS Inc., Chicago, IL, USA).

\section{RESULTS}

The total number of study subjects who were successfully genotyped for all three SNPs, rs9939609, rs1121980 and rs1558902 of FTO, was 1488. The characteristics of study subjects are shown in Table 1 . In this cohort, the average BMI was much lower than that of study subjects in previous studies. ${ }^{5,9,22,23}$ The prevalence of obesity defined as BMI $\geqslant 25 \mathrm{~kg} \mathrm{~m}^{-2}$ according to Japanese criteria was $33 \%$. DM, hypertension and MS by the Japanese definitions were exhibited by the study subjects at $7.8,44.4$ and $15.9 \%$, respectively.

From the genotyping, the prevalences of each genotype in the three SNPs were determined to be AA/AT/TT $=56 / 475 / 957$ in rs9939609, $\mathrm{AA} / \mathrm{AG} / \mathrm{GG}=81 / 519 / 885$ in $\mathrm{rs} 1121980$ and $\mathrm{AA} / \mathrm{AT} / \mathrm{TT}=59 / 468 / 959$ in rs1558902. These allele frequencies are in accordance with HardyWeinberg equilibrium (data not shown).

The three SNPs, rs9939609, rs1121980 and rs1558902 in FTO, were tested for associations with hypertension, diabetes, dyslipidemia, obesity and MS in all the subjects using $\chi^{2}$-tests. As shown in Table 2, there were no significant associations with hypertension or metabolic disorders in additive, dominant or recessive models. Table 3 shows blood pressure level and various metabolic parameters compared among genotypes for the three models of three SNPs in FTO using analysis of variance.

Additive and dominant models of rs1121980 showed significant differences in levels of IRI ( $P=0.022,0.01$, respectively) and HOMAIR $(P=0.029,0.008$, respectively), as shown in Table 3 . Table 4 shows detailed data of IRI and HOMA-IR values composed among the genotypes in rs1121980. After adjusting for confounding factors including age, gender, BMI, abdominal circumference and presence of DM, there were still significant differences in IRI and HOMA-IR among genotypes in both additive and dominant models $(P=0.005$, 0.001 , respectively) as determined by analysis of covariance.

Because some antihypertensive drugs might affect insulin sensitivity, we investigated the genotype comparison of HOMA-IR in both additive and dominant models for rs1121980 in subjects without hypertension $(n=740)$. Significant differences were again identified: AA $(n=38): \quad 1.82 \pm 4.04$ vs. $\mathrm{AG}(223): 1.09 \pm 0.84$ vs. $\mathrm{GG}(418)$ : $1.10 \pm 0.94$ in the additive model $(P=0.004)$ and AA: $1.82 \pm 4.04$ vs. $\mathrm{AG}+\mathrm{GG}(641): 1.10 \pm 0.91$ in the dominant model $(P=0.0009)$.

\section{Table 1 Characteristics of study subjects}

\begin{tabular}{|c|c|}
\hline & $\mathrm{N}=1488$ \\
\hline Age (year) & $62.7 \pm 11.63$ \\
\hline Gender ( $n$, male/female) & $M / F=582: 906(M: 39.1 \%)$ \\
\hline $\mathrm{BMI}\left(\mathrm{kg} \mathrm{m}^{-2}\right)$ & $23.81 \pm 3.24$ \\
\hline Abdominal circumference $(\mathrm{cm})$ & $83.96 \pm 10.20$ \\
\hline Systolic blood pressure (mm Hg) & $137.43 \pm 22.79$ \\
\hline Diastolic blood pressure (mm Hg) & $76.37 \pm 11.67$ \\
\hline Total cholesterol (mg per $100 \mathrm{ml}$ ) & $201.18 \pm 31.64$ \\
\hline $\mathrm{HDL}-\mathrm{CHO}$ (mg per $100 \mathrm{ml}$ ) & $50.59 \pm 12.28$ \\
\hline LDL-CHO (mg per 100 ml) & $130.04 \pm 29.62$ \\
\hline Triglyceride (mg per $100 \mathrm{ml}$ ) & $102.72 \pm 57.86$ \\
\hline FBS (mg per $100 \mathrm{ml}$ ) & $97.8 \pm 24.83$ \\
\hline $\mathrm{IRI}\left(\mu \mathrm{U} \mathrm{mI}^{-1}\right)$ & $5.203 \pm 3.71$ \\
\hline HOMA-IR & $\begin{array}{r}1.32 \pm 1.43 \\
\text { (mean } \pm \text { s.d.) }\end{array}$ \\
\hline
\end{tabular}

Abbreviations: BMI, body mass index; FBS, fasting blood sugar; $\mathrm{HDL}-\mathrm{CHO}$, high-densitylipoprotein cholesterol; IRI, immunoreactive insulin; LDL-CHO, low-density-lipoprotein cholesterol; HOMA-IR, homeostasis model assessment insulin resistance. HOMA-IR= $($ FBS $\times$ fasting IRI)/405 
Table 2 Relationships between three SNPs in FTO and metabolic diseases

\begin{tabular}{|c|c|c|c|c|c|c|c|c|c|}
\hline & \multicolumn{3}{|c|}{ rs9939609 } & \multicolumn{3}{|c|}{ rs 1121980} & \multicolumn{3}{|c|}{ rs1558902 } \\
\hline & $\begin{array}{c}\text { Additive } \\
\text { model }\end{array}$ & $\begin{array}{c}\text { Dominant } \\
\text { model } \\
A A \text { vs. } A T+T T\end{array}$ & $\begin{array}{c}\text { Recessive } \\
\text { model } \\
T T \text { vs. } A T+A A\end{array}$ & $\begin{array}{c}\text { Additive } \\
\text { model }\end{array}$ & $\begin{array}{c}\text { Dominant } \\
\text { model } \\
A A \text { vs. } A G+G G\end{array}$ & $\begin{array}{c}\text { Recessive } \\
\text { model } \\
\text { GG vs. } A G+A A\end{array}$ & $\begin{array}{c}\text { Additive } \\
\text { model }\end{array}$ & $\begin{array}{c}\text { Dominant } \\
\text { model } \\
A A \text { vs. } A T+T T\end{array}$ & $\begin{array}{c}\text { Recessive } \\
\text { model } \\
T T \text { vs. } A T+A A\end{array}$ \\
\hline Dyslipidemia & 0.5628 & 0.729 & 0.2845 & 0.5386 & 0.3025 & 0.4837 & 0.7339 & 0.5975 & 0.4805 \\
\hline Diabetes & 0.4729 & 0.4982 & 0.4221 & 0.5166 & 0.3312 & 0.7613 & 0.4923 & 0.4362 & 0.514 \\
\hline Hypertension & 0.5142 & 0.3994 & 0.3291 & 0.6366 & 0.9944 & 0.3623 & 0.5557 & 0.6346 & 0.2859 \\
\hline Obesity & 0.9303 & 0.9001 & 0.7057 & 0.8787 & 0.9718 & 0.6202 & 0.8242 & 0.9073 & 0.5357 \\
\hline \multicolumn{10}{|l|}{ Treatment history } \\
\hline Dyslipidemia & 0.86 & 0.8151 & 0.6768 & 0.6608 & 0.5948 & 0.3888 & 0.8033 & 0.9036 & 0.5535 \\
\hline Diabetes & 0.4843 & 0.2792 & 0.822 & 0.403 & 0.4852 & 0.3648 & 0.4943 & 0.3398 & 0.677 \\
\hline Hypertension & 0.4274 & 0.2045 & 0.5304 & 0.6523 & 0.3601 & 0.6956 & 0.4885 & 0.3156 & 0.3666 \\
\hline Metabolic syndrome & 0.7067 & 0.9954 & 0.4213 & 0.6112 & 0.9917 & 0.3415 & 0.6153 & 0.8625 & 0.3767 \\
\hline
\end{tabular}

Values are indicated as $P$-values.

Table 3 Relationships between three SNPs in FTO and metabolic parameters

\begin{tabular}{|c|c|c|c|c|c|c|c|c|c|}
\hline & \multicolumn{3}{|c|}{ rs9939609 } & \multicolumn{3}{|c|}{ rs1121980 } & \multicolumn{3}{|c|}{ rs1558902 } \\
\hline & $\begin{array}{c}\text { Additive } \\
\text { model }\end{array}$ & $\begin{array}{c}\text { Dominant } \\
\text { model } \\
A A \text { vs. } A T+T T\end{array}$ & $\begin{array}{c}\text { Recessive } \\
\text { model } \\
T T \text { vs. } A T+A A\end{array}$ & $\begin{array}{c}\text { Additive } \\
\text { model }\end{array}$ & $\begin{array}{c}\text { Dominant } \\
\text { model } \\
A A \text { vs. } A G+G G\end{array}$ & $\begin{array}{c}\text { Recessive } \\
\text { model } G G \\
\text { vs. } A G+A A\end{array}$ & $\begin{array}{c}\text { Additive } \\
\text { model }\end{array}$ & $\begin{array}{c}\text { Dominant } \\
\text { model } \\
A A \text { vs. } A T+T T\end{array}$ & $\begin{array}{c}\text { Recessive } \\
\text { model } \\
T T \text { vs. } A T+A A\end{array}$ \\
\hline T-CHO (mg per $100 \mathrm{ml}$ ) & 0.1799 & 0.6608 & 0.0641 & 0.3366 & 0.351 & 0.1719 & 0.3976 & 0.7541 & 0.1748 \\
\hline HDL-CHO (mg per $100 \mathrm{ml}$ ) & 0.4853 & 0.5142 & 0.4232 & 0.8663 & 0.948 & 0.6243 & 0.5043 & 0.4449 & 0.5204 \\
\hline LDL-CHO (mg per 100 ml) & 0.2946 & 0.5909 & 0.1191 & 0.5649 & 0.4123 & 0.3708 & 0.4825 & 0.7386 & 0.2273 \\
\hline TG (mg per 100 ml) & 0.872 & 0.6059 & 0.8236 & 0.6308 & 0.6027 & 0.3557 & 0.6878 & 0.4164 & 0.9499 \\
\hline FBS (mg per 100 ml) & 0.9072 & 0.7465 & 0.7072 & 0.9321 & 0.7166 & 0.9876 & 0.9539 & 0.8355 & 0.7836 \\
\hline $\mathrm{IRI}\left(\mu \mathrm{U} \mathrm{mI}^{-1}\right)$ & 0.3919 & 0.2543 & 0.3002 & 0.022 & 0.01 & 0.0876 & 0.2408 & 0.311 & 0.1145 \\
\hline HOMA-IR & 0.7414 & 0.4844 & 0.6122 & 0.0294 & 0.008 & 0.3577 & 0.6697 & 0.5585 & 0.4156 \\
\hline $\mathrm{SBP}(\mathrm{mm} \mathrm{Hg})$ & 0.7555 & 0.6449 & 0.4893 & 0.3885 & 0.8893 & 0.1772 & 0.6958 & 0.9078 & 0.3991 \\
\hline $\mathrm{DBP}(\mathrm{mm} \mathrm{Hg})$ & 0.9621 & 0.9567 & 0.7814 & 0.3831 & 0.8359 & 0.2113 & 0.7915 & 0.6504 & 0.7127 \\
\hline BMI & 0.6663 & 0.9483 & 0.3768 & 0.4627 & 0.9628 & 0.23 & 0.3762 & 0.9994 & 0.1787 \\
\hline
\end{tabular}

Abbreviations: BMI, body mass index; DBP, diastolic blood pressure; FBS, fasting blood sugar; HDL-CHO, high-density-lipoprotein cholesterol; HOMA-IR, homeostasis model assessment insulin resistance; IRI, immunoreactive insulin; LDL-CHO, low-density-lipoprotein cholesterol; SBP, systolic blood pressure; T-CHO, total cholesterol; TG, triglyceride. Values are indicated as $P$-values.

There was strong linkage disequilibrium among the three SNPs in FTO. The $r^{2}$ values were 0.811 between rs9939609 and rs1121980, 0.956 between rs9939609 and rs1558902 and 0.821 between rs1121980 and rs 1558902 . Table 5 shows the results of comparison for metabolic parameters for each haplotype of the three SNPs in additive, dominant and recessive models analyzed by analysis of variance. Low-frequency haplotypes, namely, those with frequencies below $1 \%$, were excluded from analysis. Five haplotypes were analyzed. H2 had a strong association with insulin resistance (Table 5), although it was present at a low frequency $(n=21)$.

\section{DISCUSSION}

This study is the first reported investigation of the association between genetic variations in FTO and detailed metabolic parameters in the Japanese general population. We selected three SNPs, rs9939609, rs1121980 and rs1558902 in FTO, that had been found to be strongly associated with obesity, defined by BMI, in genome-wide association
Table 4 Detailed data of IRI and HOMA-IR values compared among genotypes in rs 1121980

\begin{tabular}{llllll}
\hline SNP rs1121980 $\begin{array}{l}\text { Genotype } \\
\text { group }\end{array}$ & HOMA-IR & P-value & $I R I\left(\mu \cup m I^{-1}\right)$ & P-value \\
& GG (828) & $1.29 \pm 1.42$ & & $5.06 \pm 3.38$ & \\
AG (482) & $1.30 \pm 1.02$ & 0.006 & $5.27 \pm 3.67$ & 0.020 \\
AA (76) & $1.74 \pm 2.99$ & & $6.26 \pm 6.34$ & \\
& & & & \\
GG & $1.29 \pm 1.42$ & & $5.05 \pm 3.38$ & 0.421 \\
AG+AA & $1.36 \pm 1.46$ & 0.794 & $5.41 \pm 4.15$ & \\
& & & & \\
GG+AG & $1.29 \pm 1.29$ & 0.002 & $5.14 \pm 3.49$ & 0.013 \\
AA & $1.73 \pm 2.99$ & & $6.26 \pm 6.34$ &
\end{tabular}

Abbreviations: HOMA-IR, homeostasis model assessment insulin resistance; IRI, immunoreactive insulin; SNP, single nucleotide polymorphism. immunoreactive insulin; SNP, sing
Values are shown as mean \pm s.d.

Subjects with data of HOMA-IR and IRI were analyzed in Table 4. 
Table 5 The results of comparison between haplotypes with three SNPs for metabolic parameters

\begin{tabular}{llcccc}
\hline & rs9939609/rs1121980/rs1558902 & T-CHO & HDL-CHO & LDL-CHO & IRI \\
\hline H1 & AA/AA/AA (56) vs. others & 0.6608 & 0.5142 & 0.5909 & 0.2543 \\
H2 & AT/AA/AT (21) vs. others & 0.1853 & 0.2637 & 0.3121 & $0.0006^{\mathrm{a}}$ \\
H3 & AT/AG/AT (441) vs. others & 0.2977 & 0.5497 & 0.3463 & 0.9984 \\
H4 & TT/AG/TT (67) vs. others & 0.8063 & 0.4806 & 0.4044 & 0.5983 \\
H5 & TT/GG/TT (878) vs. others & 0.1305 & 0.5129 & 0.3147 & 0.4927 \\
\hline
\end{tabular}

Abbreviations: HDL-CHO, high-density-lipoprotein cholesterol; HOMA-IR, homeostasis model assessment insulin resistance; IRI, immunoreactive insulin; LDL-CHO, low-density-lipoprotein cholesterol; T-CHO, total cholesterol.

Values are indicated as $P$-values.

aAT/AA/AT $8.11 \pm 9.89 \quad(N=19)$. Others $5.16 \pm 3.54 \quad(N=1370)$.

${ }^{\mathrm{b} A T / A A / A T} \quad 2.72 \pm 5.59 \quad(N=19)$. Others $1.30 \pm 1.28 \quad(N=1370)$.

studies in various ethnicities. ${ }^{22,24-29}$ In Japan, Hotta et al. ${ }^{9}$ reported that rs1558902 in FTO was most significantly associated with obesity in a case-control association study using severely obese Japanese subjects (average $\mathrm{BMI} \geqslant 30 \mathrm{~kg} \mathrm{~m}^{-2}$ ). ${ }^{9}$ In this study, we investigated the association between various metabolic parameters including hypertension, DM, obesity and MS in subjects participating in the Tanno-Sobetsu cohort study, a study of a Japanese representative rural cohort in Hokkaido. The average BMI of the study subjects was $23.81 \pm 3.24 \mathrm{~kg} \mathrm{~m}^{-2}$, which is close to the national average in Japan. In this study, none of the three SNPs was associated with obesity, defined by BMI, higher abdominal circumference or prevalence of MS, defined by Japanese criteria. In addition, none of the three SNPs was associated with hypertension, dyslipidemia or prevalence of DM.

Only one SNP, rs1121980, showed a strong correlation with HOMA-IR, which is an index of insulin resistance, in additive and dominant models. Subjects with AA in rs1121980 had a much higher HOMA-IR and a higher insulin resistance than subjects without the AA genotype $(P=0.008)$. This $P$-value is considered significant $(P<0.017)$ after Bonferroni's correction to adjust for multiple testing of the three SNPs. Subjects with the haplotype H2, which includes AA in rs1121980, had a higher HOMA-IR than other subjects (Table 5). Thus, we conclude that rs1121980 in FTO is associated with insulin resistance in the Japanese general population. Because a recent report indicates that a gain of function of FTO induces insulin resistance, ${ }^{7}$ rs1121980 located in an intron may regulate FTO gene function by affecting splicing variation. After adjusting for obesity and the prevalence of DM, rs1121980 is independently associated with insulin resistance. Therefore, rs1121980 may affect insulin resistance, directly and not only indirectly by obesity.

In this study, three SNPs in FTO were not associated with obesity. Several reasons for this are considered. One is the difference between Caucasian and Japanese general populations in the severity of obesity. In fact, SNPs in FTO were associated with obesity in a study using Japanese subjects with severe obesity (average BMI $\geqslant 30 \mathrm{~kg} \mathrm{~m}^{-2}$ ). ${ }^{9}$ Another reason is the differences in allele frequency among FTO SNPs. In the cases of rs9939609, allele frequency information obtained from HapMap database (http://hapmap.ncbi.nlm.nih.gov/) shows significant differences between Caucasian $(\mathrm{AA} / \mathrm{AT} / \mathrm{TT}=0.117 / 0.667 /$ $0.217)$ and Japanese populations (0.067/0.200/0.733).

In summary, an SNP located in an intron, rs1121980, and a haplotype of three SNPs in FTO that includes this SNP, may be important in the progression of insulin resistance in Japanese subjects. This SNP may be an independent risk factor for future MS, hypertension and DM in Japanese subjects. However, this study has limitations because of its cross-sectional design. Prospective studies investigating the relationship between these SNPs and the development of MS, hypertension and DM over a long time scale are necessary.

\section{ACKNOWLEDGEMENTS}

We thank Ms Kazuko Iwasa for continuous support of this investigations. This study was supported by research grant from the Japanese Ministry of Health, Labor, and Welfare and Osaka Heart Club.

1 Iso H, Sato S, Kitamura A, Imano H, Kiyama M, Yamagishi K, Cui R, Tanigawa T, Shimamoto T. Metabolic syndrome and the risk of ischemic heart disease and stroke among Japanese men and women. Stroke 2007; 38: 1744-1751.

2 Chei CL, Yamagishi K, Tanigawa T, Kitamura A, Imano H, Kiyama M, Sato S, Iso H. Metabolic syndrome and the risk of ischemic heart disease and stroke among middleaged Japanese. Hypertens Res 2008; 31: 1887-1894.

3 Maeda N, Shimomura I, Kishida K, Nishizawa H, Matsuda M, Nagaretani H, Furuyama N, Kondo H, Takahashi M, Arita Y, Komuro R, Ouchi N, Kihara S, Tochino Y, Okutomi K, Horie M, Takeda S, Aoyama T, Funahashi T, Matsuzawa Y. Diet-induced insulin resistance in mice lacking adiponectin/ACRP30. Nat Med 2002; 8: 731-737.

4 Scuteri A, Sanna S, Chen WM, Uda M, Albai G, Strait J, Najjar S, Nagaraja R, Orrú M, Usala G, Dei M, Lai S, Maschio A, Busonero F, Mulas A, Ehret GB, Fink AA, Weder AB, Cooper RS, Galan P, Chakravarti A, Schlessinger D, Cao A, Lakatta E, Abecasis GR. Genome-wide association scan shows genetic variants in the FTO gene are associated with obesity related traits. PLoS Genet 2007; 3: 1200-1210.

5 Hinney A, Nguyen TT, Scherag A, Friedel S, Brönner G, Müller TD, Grallert H, Illig T, Wichmann HE, Rief W, Schäfer H, Hebebrand J. Genome wide association (GWA) study for early onset extreme obesity supports the role of fat mass and obesity associated gene (FTO) variants. PLOS ONE 2007; 12: e1361-e1365.

6 Frayling TM. Genome-wide association studies provide new insights into type 2 diabetes aetiology. Nat Rev Genet 2007; 8: 657-662.

7 Fischer J, Koch L, Emmerling C, Vierkotten J, Peters T, Brüning JC, Rüther U. Inactivation of the Fto gene protects from obesity. Nature 2009; 458: 894-898.

8 Cornes BK, Lind PA, Medland SE, Montgomery GW, Nyholt DR, Martin NG. Replication of the association of common rs9939609 variant of FTO with increased BMI in an Australian adult twin population but no evidence for gene by environment $(\mathrm{G} \times \mathrm{E})$ interaction. Int J Obes (London) 2009; 33: 75-79.

9 Hotta K, Nakata Y, Matsuo T, Kamohara S, Kotani K, Komatsu R, Itoh N, Mineo I, Wada J, Masuzaki H, Yoneda M, Nakajima A, Miyazaki S, Tokunaga K, Kawamoto M, Funahashi T, Hamaguchi K, Yamada K, Hanafusa T, Oikawa S, Yoshimatsu H, Nakao K, Sakata T, Matsuzawa Y, Tanaka K, Kamatani N, Nakamura Y. Variations in the FTO gene are associated with severe obesity in the Japanese. J Hum Genet 2008; 53 : 546-553.

10 Frayling TM, Timpson NJ, Weedon MN, Zeggini E, Freathy RM, Lindgren CM, Perry JR, Elliott KS, Lango H, Rayner NW, Shields B, Harries LW, Barrett JC, Ellard S, Groves CJ, Knight B, Patch AM, Ness AR, Ebrahim S, Lawlor DA, Ring SM, Ben-Shlomo Y, Jarvelin MR, Sovio U, Bennett AJ, Melzer D, Ferrucci L, Loos RJ, Barroso I, Wareham NJ, Karpe F, Owen KR, Cardon LR, Walker M, Hitman GA, Palmer CN, Doney AS, Morris AD, Smith GD, Hattersley AT, McCarthy MI. A common variant in the FTO gene is associated with body mass index and predisposes to childhood and adult obesity. Science 2007; 316: 889-894.

11 Omori S, Tanaka Y, Takahashi A, Hirose H, Kashiwagi A, Kaku K, Kawamori R, Nakamura Y, Maeda S. Association of CDKAL1, IGF2BP2, CDKN2A/B, HHEX, SLC30A8 and KCNJ11 with susceptibility to type 2 diabetes in a Japanese population. Diabetes 2008; 57: 791-795.

12 Fujiwara T, Saitoh S, Takagi S, Ohnishi H, Ohata J, Takeuchi H, Isobe T, Chiba Y, Katoh $\mathrm{N}$, Akasaka $\mathrm{H}$, Shimamoto K. Prevalence of asymptomatic arteriosclerosis obliterans and its relationship with risk factors in inhabitants of rural communities in Japan: Tanno-Sobetsu study. Atherosclerosis 2004; 177: 83-88.

13 Ohnishi H, Saitoh S, Takagi S, Ohata J, Isobe T, Kikuchi Y, Takeuchi H, Shimamoto K. Pulse wave velocity as an indicator of atherosclerosis in impaired fasting glucose: the Tanno and Sobetsu study. Diabetes Care 2003; 26: 437-440.

14 Ohnishi H, Saitoh S, Ura N, Takagi S, Obara F, Akasaka H, Oimatsu H, Shimamoto K. Relationship between insulin resistance and accumulation of coronary risk factors. Diabetes Obes Metab 2002; 4: 388-393. 
15 Takeuchi H, Saitoh S, Takagi S, Ohnishi H, Ohhata J, Isobe T, Shimamoto K. Metabolic syndrome and insulin resistance in Japanese males Tanno-Sobetsu study. J Jpn Diabet Soc 2003; 46: 739-744.

16 Takeuchi H, Saitoh S, Takagi S, Ohnishi H, Ohhata J, Isobe T, Shimamoto K. Metabolic syndrome and cardiac disease in Japanese men: applicability of the concept of metabolic syndrome defined by the National Cholesterol Education ProgramAdult Treatment Panel III to Japanese men the Tanno and Sobetsu study. Hypertens Res 2005; 28: 203-208.

17 Akasaka H, Katsuya T, Saitoh S, Sugimoto K, Fu Y, Takagi S, Ohnishi H, Rakugi H, Ura $\mathrm{N}$, Shimamoto K, Ogihara T. Effects of angiotensin II type 1 receptor gene polymorphisms on insulin resistance in a Japanese general population: the Tanno-Sobetsu study. Hypertens Res 2006; 29: 961-967.

18 Definition and the diagnostic standard for metabolic syndrome-Committee to Evaluate Diagnostic Standards for Metabolic Syndrome. Nippon Naika Gakkai Zasshi 2005; 94 : 794-809.

19 Matthews DR, Hosker JP, Rudenski AS, Naylor BA, Treacher DF, Turner RC. Homeostasis model assessment: insulin resistance and beta-cell function from fasting plasma glucose and insulin concentrations in man. Diabetologia 1985; 28: 412-419.

20 Legry V, Cottel D, Ferrières J, Arveiler D, Andrieux N, Bingham A, Wagner A, Ruidavets JB, Ducimetière $P$, Amouyel $P$, Meirhaeghe A. Effect of an FTO polymorphism on fat mass, obesity, and type 2 diabetes mellitus in the French MONICA Study. Metabolism 2009; 58: 971-975.

21 Grunnet LG, Brøns C, Jacobsen S, Nilsson E, Astrup A, Hansen T, Pedersen O, Poulsen P, Quistorff B, Vaag A. Increased recovery rates of phosphocreatine and inorganic phosphate after isometric contraction in oxidative muscle fibers and elevated hepatic insulin resistance in homozygous carriers of the A-allele of FTO rs9939609. J Clin Endocrinol Metab 2009; 94: 596-602.

22 Jess T, Zimmermann E, Kring SI, Berentzen T, Holst C, Toubro S, Astrup A, Hansen T, Pedersen O, Sørensen TI. Impact on weight dynamics and general growth of the common FTO rs9939609: a longitudinal Danish cohort study. Int J Obes (London) 2008; 32: 1388-1394.

23 Jacobsson JA, Klovins J, Kapa I, Danielsson P, Svensson V, Ridderstråle M, Gyllensten $\mathrm{U}$, Marcus C, Fredriksson R, Schiöth HB. Novel genetic variant in FTO influences insulin levels and insulin resistance in severely obese children and adolescents. Int J Obes (London) 2008; 32: 1730-1735.

24 Scott LJ, Mohlke KL, Bonnycastle LL, Willer CJ, Li Y, Duren WL, Erdos MR, Stringham HM, Chines PS, Jackson AU, Prokunina-Olsson L, Ding CJ, Swift AJ, Narisu N, Hu T, Pruim R, Xiao R, Li XY, Conneely KN, Riebow NL, Sprau AG, Tong M, White PP, Hetrick KN, Barnhart MW, Bark CW, Goldstein JL, Watkins L, Xiang F, Saramies J, Buchanan TA, Watanabe RM, Valle TT, Kinnunen L, Abecasis GR, Pugh EW, Doheny KF, Bergman RN, Tuomilehto J, Collins FS, Boehnke M. A genome-wide association study of type 2 diabetes in Finns detects multiple susceptibility variants. Science 2007; 316: 1341-1345.

25 Ohashi J, Naka I, Kimura R, Natsuhara K, Yamauchi T, Furusawa T, Nakazawa M, Ataka Y, Patarapotikul J, Nuchnoi P, Tokunaga K, Ishida T, Inaoka T, Matsumura Y, Ohtsuka R. FTO polymorphisms in oceanic populations. J Hum Genet 2007; 52: 1031-1035.

26 Zimmermann E, Kring SI, Berentzen TL, Holst C, Pers TH, Hansen T, Pedersen O, Sørensen TI, Jess T. Fatness-associated FTO gene variant increases mortality independent of fatness - in cohorts of Danish men. PLoS One 2009; 4: e4428.

27 Renström F, Payne F, Nordström A, Brito EC, Rolandsson O, Hallmans G, Barroso I, Nordström P, Franks PW, GIANT Consortium. Replication and extension of genomewide association study results for obesity in 4923 adults from northern Sweden. Hum Mol Genet 2009; 18: 1489-1496.

28 Meyre D, Delplanque J, Chèvre JC, Lecoeur C, Lobbens S, Gallina S, Durand E, Vatin V, Degraeve F, Proença C, Gaget S, Körner A, Kovacs P, Kiess W. Tichet J, Marre M, Hartikainen AL, Horber F, Potoczna N, Hercberg S, Levy-Marchal C, Pattou F, Heude B, Tauber M, McCarthy MI, Blakemore AI, Montpetit A, Polychronakos C, Weill J, Coin LJ, Asher J, Elliott P, Järvelin MR, Visvikis-Siest S, Balkau B, Sladek R, Balding D, Walley A, Dina C, Froguel P. Genome-wide association study for early-onset and morbid adult obesity identifies three new risk loci in European populations. Nat Genet 2009; 41: 157-159.

29 Do R, Bailey SD, Desbiens K, Belisle A, Montpetit A, Bouchard C, Pérusse L, Vohl MC, Engert JC. Genetic variants of FTO influence adiposity, insulin sensitivity, leptin levels, and resting metabolic rate in the Quebec Family Study. Diabetes 2008; 57: 1147-1150. 